CALDO, Paula, Un cachito de cocinera. Mujeres, libros y recetas de cocina en la Argentina de fines del siglo XIX y principios del XX, Editorial Casagrande, Rosario, 2017, 233 páginas.

Carolina FACCIOTTI

Avances del Cesor, V. XIV, No 17, diciembre 2017, pp. 155-159.

ISSNe 2422-6580 / ISSN 1514-3899 - http://web2.rosario-conicet.gov.ar/ojs/index.php/AvancesCesor/index

\title{
CALDO, Paula, Un cachito de cocinera. Mujeres libros y recetas de cocina en la Argentina de fines el siglo XIX y principios del XX, Editorial Casagrande, Rosario, 2017, 233 páginas.
}

\author{
Carolina Facciotti \\ Instituto Altos Estudios Sociales \\ Universidad Nacional de San Martín \\ (Argentina) \\ carolinafacciotti@hotmail.com
}

La preocupación por el estudio de los modos del comer y alimentarnos, en tanto hecho sociocultural, y el rol de la mujeres en las prácticas culinarias como marca identitaria, son temas en los que, la historiadora Paula Caldo, ha concentrado su líneas de trabajo. El presente libro, Un cachito de cocinera, no es ajeno a ello y llega para sumarse al ya publicado en 2009, Mujeres Cocineras. ${ }^{1}$

En esta ocasión, Caldo nos acerca un arduo trabajo de investigación sobre la relación de las mujeres con la escritura y el mundo de la cocina

1. Caldo, Paula, Mujeres cocineras. Hacia una historia sociocultural de la cocina Argentina a fines del siglo XIX y primera mitad del XX, Editorial Prohistoria, Rosario, 2009. en la Argentina en el cruce de los siglos XIX y XX. Precisamente, la autora propone pensar cómo la publicación de recetarios o libros de cocina constituyó uno de los intersticios a partir de los cuales las mujeres podían emerger en el espacio público como escritoras. Pero, a su vez, la investigación propuesta ahonda en el interior del propio género femenino, es decir, en los modos en que señoras letradas y cocineras, ubicadas en espectros socioeconómicos disímiles se encontraban en un marco de negociación de sentidos e intercambios simbólicos del saber culinario, teniendo por objeto los procedimientos y modos en los se preparaban y presentaban los alimentos transformados en platos a degustar.

En las cinco secciones que recorre el libro se deja entrever ese interés. Para el primer capítulo recupera las biografías de tres mujeres escritoras, "señoras que escriben": Juana Manuela Gorriti, Marta Cullen de Aldao (Marta) y Susana Torres de Castex (Teófila). 
Tres autoras, señoras cultas amantes de las letras que aspiraban a un reconocimiento público de su escritura. Decimos tres autoras y no cocineras, porque tal como se logra demostrar, en los tres casos estas mujeres se dedicaban a compilar y compendiar un conjunto de recetas de diverso origen $y$ tradición. Asíla autora reza: "Aunque entre este trío femenino mediaron algunas diferencias notables, existieron también similitudes que las ubican como damas de la Argentina de fines de siglo XIX y comienzos del XX. Una fue la publicación de un recetario de cocina, pero existió otra más profunda: la confianza en que todas las mujeres tenemos un cachito de cocineras". ${ }^{2}$

Las dos primeras secciones del libro introducen al lector en el análisis del saber culinario en tanto dimensión de la práctica. Un saber-hacer que se expresa en el acto mismo de su ejecución. De allí que se interroga sobre ese saber especifico que se transmite en la cocina. Es un saber doméstico que se diferencia de aquel otro elaborada en los restaurantes y demás espacios de sociabilidad pública. División de trabajo en la cual la mujer se instituye como cocinera y el varón asume la fase pública. En ese reparto, las mujeres asumen las labores domésticas, entre ellas el acto de cocinar para las familias. Un conocimiento inscripto en el saber-hacer de una obra efímera, evanescente que culmina con la ingesta de la comida, pero que se perpetúa con el trabajo de transmisión a través de estos libros impresos: los recetarios de cocina. Una escritura sencilla y concreta con procedimientos y consejos culinarios que resguarda del olvido a los saberes y que están destinados a regir sobre las prácticas culinarias

2. Caldo, Paula, Un cachito de cocineras, Editorial Casagrande, Rosario 2017, p. 18.

156 y que se anuncian con una fuerza prescriptiva que busca el disciplinamiento de la cocinera.

Ejemplo de ello es Juana Manuela de Gorriti, una dama salteña con notable capacidad de combinar la labor de escritora y de educadora con los quehaceres domésticos. Bajo un formato de compilación, Juana reunió un conjunto de recetas de amigas y familiares que colaboraron con el contenido de su Cocina Ecléctica, recuperando la cocina criolla latinoamericana. Gorriti puso en palabras escritas los más diversos recetarios. Las diferencias de ideologías de procedencia social, de oficio y formación acentuaron aún más el carácter diverso del producto final y condensaron las distintas expresiones culinarias del gusto preferido de los sectores dominantes latinoamericanos de antaño.

La autora analiza en este capítulo los modos en que la comida fue eje de sociabilidad de las clases acomodadas. Su valor radicó menos en la cantidad y en las sustancias nutricias, que en la calidad, las formas y los contextos de consumo.

Señoras y cocineras, en un intercambio de saberes yen una cadena de transmisión que parte del registro de la oralidad y la práctica propia de cocineros, se encuentran en una degustación de comidas, hasta desembocar en el interés de las damas por las recetas y su consecuente publicación escrita. Como indicaba la regla, toda mujer, independientemente del estrato social al que pertenecieran debía despertar la cocinera que llevaba dentro. Ser mujer ya era una "condición de posibilidad de ser cocinera".

Siguiendo el concepto de Jaques Ranciére sobre el reparto de lo sensible, Caldo analiza la división tácita que se establece entre, por un lado, las mujeres que podían asumir la 
escritura de la cocina desafiando la hegemonía masculina imperante en el universo de las producciones culturales, es decir las señoras, $y$, por el otro ,las cocineras que, como personal doméstico, dictaban aquellas fórmulas culinarias quedando al margen de la escritura como posibilidad de hacerse visibles. De este modo, Caldo sugiere la idea de los recetarios de la época como libros corales, voces femeninas en particular, que bajo la dirección de Juana Manuela, conformaban la creación de una compilación de saberes culinarios escritos por mujeres para mujeres.

De este modo, la autora sostiene en este punto cómo a fines de siglo XIX y comienzos del XX las mujeres situadas en las cocinas, optaron por apropiarse de lo recibido y hacer cosas a partir de sus posibilidades. Algunas se limitaron a cocinar, pero otras se decidieron a hacer de la herencia un campo de saber propio que les permitió transmitir y publicar libros aunque expresaran una polifonía de voces del saber culinario.

Ya en la sección tercera, se aborda la trastienda de esos ejercicios de escritura y para ello son estudiados los estilos discursivos con que fueron publicadas estas recetas por parte de Juana Manuela, Teófila y Marta. Si bien cada recetario se presentó bajo un formato de largas listas, cada uno mostró un modo particular de exhibirlas. $\mathrm{Y}$ es precisamente en estos modos de presentar las recetas donde, de acuerdo a la autora, se ocultan los indicios relativos a las negociaciones y conflictos generados durante el proceso de producción de estos textos.

De allí que Caldo se pregunta: ¿Quiénes eran las dueñas de las recetas? ¿Las señoras escritoras o las cocineras de oficio o ambas?
Este modo del discurso de la receta y la prosa que las enmarca se presentan básicamente bajo formas de procedimientos en un estilo narrativo que captura la materialidad de la cocina: ingredientes, elementos-utensilios, prácticas y comidas, lleva a la autora a pensar como a la vez se está jugando un imaginario de las cocineras que se reordena en la escritura del saber culinario. Éste se encontraba inscripto en las manos que, en ese imaginario, se adhería a la naturaleza femenina: ser mujer implicaba saber cocinar, pero además expresaba un arte de hacer que con el tiempo capturaría a la letra. Serían estas señoras escritoras, adineradas, amantes del buen comer y de los viajes quienes, para escribir sus libros, tuvieron que acercarse a la habitación destinada a la cocina y, desde allí, sumergirse en los secretos de las cocineras. Un acercamiento no exento de tensiones que debió encontrar entre cocineras y escritoras un marco de negociación de sentidos que se yuxtaponían y expresaban en el producto final, es decir, los recetarios, dando por resultado una textura particular a las recetas.

Un proceso de conversión de la acción de las cocineras, hacedoras directas de las grafías de la escritura que lleva a Caldo a preguntarse por los indicios de la oralidad que las habitaron y a sostener que este encuentro entre mujeres cocineras y mujeres letradas afectó el orden mismo del saber culinario. Pero también,-estos libros activaron un proceso inverso: las señoras leyeron en voz alta las fórmulas culinarias mientras sus empleadas se apropiaban del contenido y lo ejecutaban.

Ahora bien, en la sección siguiente se plantean nuevos interrogantes: ¿cuáles eran esas recetas? ¿Qué contenidos y formas presentaban esos platos? ¿Qué ingredientes utilizaban? ¿Qué utensilios y herramientas se indicaban? 
¿Qué transformaciones se operaban sobre los alimentos? ¿Qué formas de cocción prevalecieron? Siguiendo con el análisis de las tres escritoras de recetarios que toma la autora como casos testigo para su trabajo, es decir Juana Manuela, Marta y Teófila, se observa cómo se diferenciaban.

De este modo, Caldo pone en relieve los patrones alimentarios predominantes en la Argentina en el cruce de los siglos XIX y XX a saber: los resabios de la cocina propia de los pueblos originarios, a la cual se le sumaba el aporte de la cocina criolla, y que luego todo ello mutaría con la intervención de la cocina cosmopolita proveniente de Europa. En este intercambio la autora señala cómo en el devenir del tiempo, se fue perdiendo la apuesta original emergiendo una cocina ecléctica y mestiza, que seducía en América, pero también hacía lo propio en Europa. De esta manera, los recetarios combinaban sabores y placeres, pero también daban cuenta del cuidado de la salud, la amistad, la seducción de la religión.

Hacia el final de su trabajo, en su quinta sección, Caldo se ocupa del otro extremo de la cadena de la transmisión. Si eran las mujeres escritoras y compiladoras de recetas quienes iniciaban a través de la escritura el registro escrito que le aportaban las cocineras, entonces, dice Caldo nos queda por indagar el sujeto receptor de esta cadena: las mujeres del hogar. Siempre instalada en ese tiempo histórico, la autora va indicando como la cocina doméstica se estableció orientada a los hogares, y especialmente a las amas de casas. Por lo tanto, estamos ante libros escritos por mujeres y dirigidos a mujeres, y que portan un saber práctico e instructivo y por ende altamente performativo. En ese sentido, sostiene Caldo, la experiencia de lectura que desencadenaban estos recetarios repercutían en la identidad de las lectoras: ellas eran mujeres lectoras de textos redactados, ya no por varones, sino por sus congéneres y sobre temas relativos a los quehaceres propios del género. Recetas escritas en un estilo discursivo netamente procedimental que invitaban a hacer y no a pensar. Objetos de lectura que se guardaban en las cocinas y no en bibliotecas y que circulaban de mano en mano. Pero, aunque se siguiera la regla exacta que indicaba la receta, siempre aparecía lo nuevo que se introducía como novedad estableciendo la diferencia.

Es interesante cómo la autora hace notar el carácter altamente performativo de estos textos portadores de un saber centrado en lo culinariao que operaban sobre los gestos, las acciones y los cuerpos de las mujeres -tanto empleadas domésticas como señorasdeterminando el rol de la ama de casa.

Un cachito de cocinera, mujeres libros y recetas de cocina en la Argentina de fines del siglo XIX $y$ principios del $X X$, constituye un bello trabajo académico, de una escritura transparente y de lectura amena, aunque no exento de una rigurosidad exhaustiva que denota un esforzado trabajo de análisis de fuentes, en este caso los recetarios, y por la puesta en diálogo con categorías analíticas muy pertinentes retomando autores fundamentales como Graciela Batticuore, Roger Chartier, Norbert Elias, Jorge Larrosa, Jacques Ranciére, Jacques Hassoun, Judith Butler, Natalie Zemon Davis, Fernando Rocchi, entre otros. Cada uno de ellos aportó aristas que enriquecen sumamente la hipótesis de este trabajo. Aplaudimos el arribo de esta obra necesaria para seguir pensando el género femenino, los recetarios y sus efectos performativos. 
Recibido: 14-10-2017

Aceptado: 22-11-2017

Publicado: 05-12-2017 